\title{
The analysis of tool life and wear mechanisms in spindle speed variation machining
}

\author{
P. Albertellia*, V. Mussi ${ }^{\mathrm{b}}$, M. Monno ${ }^{\mathrm{a}}$ \\ ${ }^{a}$ Mechanical Engineering Department, Politecnico di Milano, Via La Masa 1, 20156 Milan (Italy) \\ ${ }^{b}$ Laboratorio MUSP, Via Tirotti 9, 29122 Piacenza (Italy) \\ * Corresponding author. Tel.: +390223998557; fax: +390223998585. E-mail address: paolo.albertelli@polimi.it.
}

\begin{abstract}
Regenerative chatter vibrations generally limit the achievable material removal rate (MRR) in machining. The diffusion of spindle speed variation (SSV) as a chatter suppression strategy is mainly restricted to academy and research centers. A lack of knowledge concerning the effects of non-stationary machining is still limiting its use in real shop floors. This research is focused on the effects of spindle speed variation technique on tool duration and on wear mechanisms. No previous researches have been performed on this specific topic. Tool wear tests in turning were carried out following a factorial design: cutting speed and cutting speed modulation were the investigated factors. The carbide life was the observed process response. A statistical approach was used to analyze the effects of the factors on the tool life. Moreover, the analysis was extended to the wear mechanisms involved during both constant speed machining (CSM) and SSV. The worn out carbide surfaces were examined under a scanning electron microscope (SEM) equipped with an energy dispersive X-ray spectrometer (EDS). Significant differences were appreciated. It was observed that SSV tends to detach the coatings of the inserts, entailing a mechanism that is quite unusual in wet steel turning and thus fostering the wear of the tool. The performed analysis allowed to deduce that the intensified tool wear (in SSV cutting) is mainly due to thermo-mechanical fatigue.
\end{abstract}

Keywords: tool wear; chatter; spindle speed variation

\section{Introduction}

The regenerative chatter occurrence, as described by Altintas and Weck [1], involves high tool and or workpiece vibrations, bad surface finishing and reduced tool life and thus limits the achievable Material Removal Rate (MRR).

Although regenerative chatter drastically affects the achievable productivity in machining, only a few researchers studied the effects of vibration on tool life and consequently on the related production costs. Kayhan and Budak in [2] performed tool life tests (both in turning and in milling) under regenerative chatter regime. A drastic tool life reduction was observed: up to 80 percent in turning and up to 50 percent in milling depending on chatter severity. This study justifies the continuous academic and industrial research efforts on chatter avoidance and suppression. As explained by Siddhpura and Paurobally [3], the stability lobes diagram (SLD) can be used to select the chatter free depths of cut. Spindle speed variation (SSV) is a well-known technique to suppress regenerative machine tool vibrations: the continuous modulation of the spindle speed is able to break the energy that flows from the cutting process to the machine/workpiece thus preventing the occurrence of undesired vibrations. Inamura and Sata [4] presented one of the first works on SSV. Due to its flexibility and its easy implementation, spindle speed variation is a very promising chatter suppression strategy even compared with other developed methods. In the scientific literature, different modulating spindle strategies were studied. For instance, Yilmaz et al. [5] proposed a spindle speed variation based on a multi-level random signal. Insperger et al. [6] studied analytically and numerically the stabilizing properties of sinusoidal spindle speed variation (SSSV). SSSV seems the most interesting implementation of the SSV. This is not only due to its stabilizing properties: SSSV involves only finite acceleration values that are more easily processed and tracked by drives and numerical controllers (NC). Although a lot of research effort was done over the years, the technique is not still used in real shop floors. Different issues can represent potential limitations to the wide diffusion of SSV. First, the lack of easy, robust and recognized guidelines that can be exploited to select the most adequate SSSV parameters given a specific industrial application. Some researchers worked on this issue. Radulescu et al. [7] used time domain numerical models to predict the cutting performance during a non-constant speed machining. Jayaram et al. [8] developed a new analytical model to predict chatter stability with spindle speed machining. Some researches proposed methodologies to estimate SLD when SSV is adopted. Insperger and Stépán [9] used the semi-discretization method to estimate chatter free regions in SSSV turning. Zatarin et al. [10] presented a general theory to analyze SSSV in milling in the frequency domain; the approach is suited for any spindle speed variation strategy.

In spite of a lot of research done over the years, there is still a lack of know-how concerning the phenomena involved in the chip formation and in the spindle system when SSV is used. For example, it could be helpful to estimate the thermal overload and the power consumption the electrical spindle motor is subjected to when SSV is adopted. Moreover, it could be interesting to characterize the processed surface when SSV machining is used. Albertelli et al. [11] presented some analyses on a few of these matters. Moreover, the research community should deal with many not examined matters in 
order to improve the awareness on the SSV potentialities: it is necessary to focus not only on the already proved vibration mitigation properties but also on any other potential detrimental aspects. In this research, an experimental analysis both on tool life and on wear mechanisms in SSSV turning is presented. To the authors' knowledge, no previous researches have been done on this topic.

As can be well observed in Fig. 1, SSV mainly allows a significant expansion of the chatter free region (green area), providing higher chatter-free depths of cut (considering the SLD of Machine A) over a wide range of cutting speeds.

Being able to know if SSV affects the life of the tool could therefore be useful to analyze two interesting and reasonable scenarios. First, in order to be sure to avoid chatter vibration a machine tool operator could decide to use systematically the SSV, especially if the machine (Machine A) is not equipped with a reliable and robust chatter detection/control module. What will the operator have to expect regarding the life of the tool? In particular, it would be interesting to analyze the effects of the modulation of the cutting speed on the life of the tool when SSV is used in originally stable cutting conditions (i.e. $\mathrm{S}_{\mathrm{A}}$ : stable cutting conditions for machine A, Fig. 1). Indeed, it is already well known that the avoidance of chatter involves positive effects on tool integrity and on tool life [2]: the expected tool life working in stabilized (i.e. $\mathrm{S}_{\mathrm{A}+\mathrm{SSV}}$ : stabilized cutting conditions, machine A) cutting conditions is much higher than working in unstable conditions (i.e. $\mathrm{U}_{\mathrm{A}}$ : unstable cutting conditions, machine A). In such a way, SSV allows to overcome the limitations of the machine (machine A). Regarding the second scenario, the same cutting performance in terms of material removal rate MRR (machine A with $\mathrm{SSV}, \mathrm{S}_{\mathrm{A}+\mathrm{SSV}}$ ) can therefore be obtained also using a more rigid machine (Machine $\mathrm{B}$ that is also typically more expensive) that exhibits higher chatter free depths of cut (i.e. $S_{B}$ stable cutting conditions, machine B). If a shorter tool life is expected for cutting conditions represented by $\mathrm{S}_{\mathrm{A}+\mathrm{SSV}}$ (machine A and SSV) a tradeoff need to be tackled: is it better to use a more rigid machine (more expensive) or to use a cheaper machine (less rigid) with SSV that could involve a more relevant tool wear? Moreover, if a wear model for the tool in each machining condition (same MRR but stable $\mathrm{S}_{\mathrm{B}}, \mathrm{U}_{\mathrm{A}}$ and $\mathrm{S}_{\mathrm{A}+\mathrm{SSV}}$ ) was available it would allow comparing more formally different cutting situations also evaluating production time and production costs.

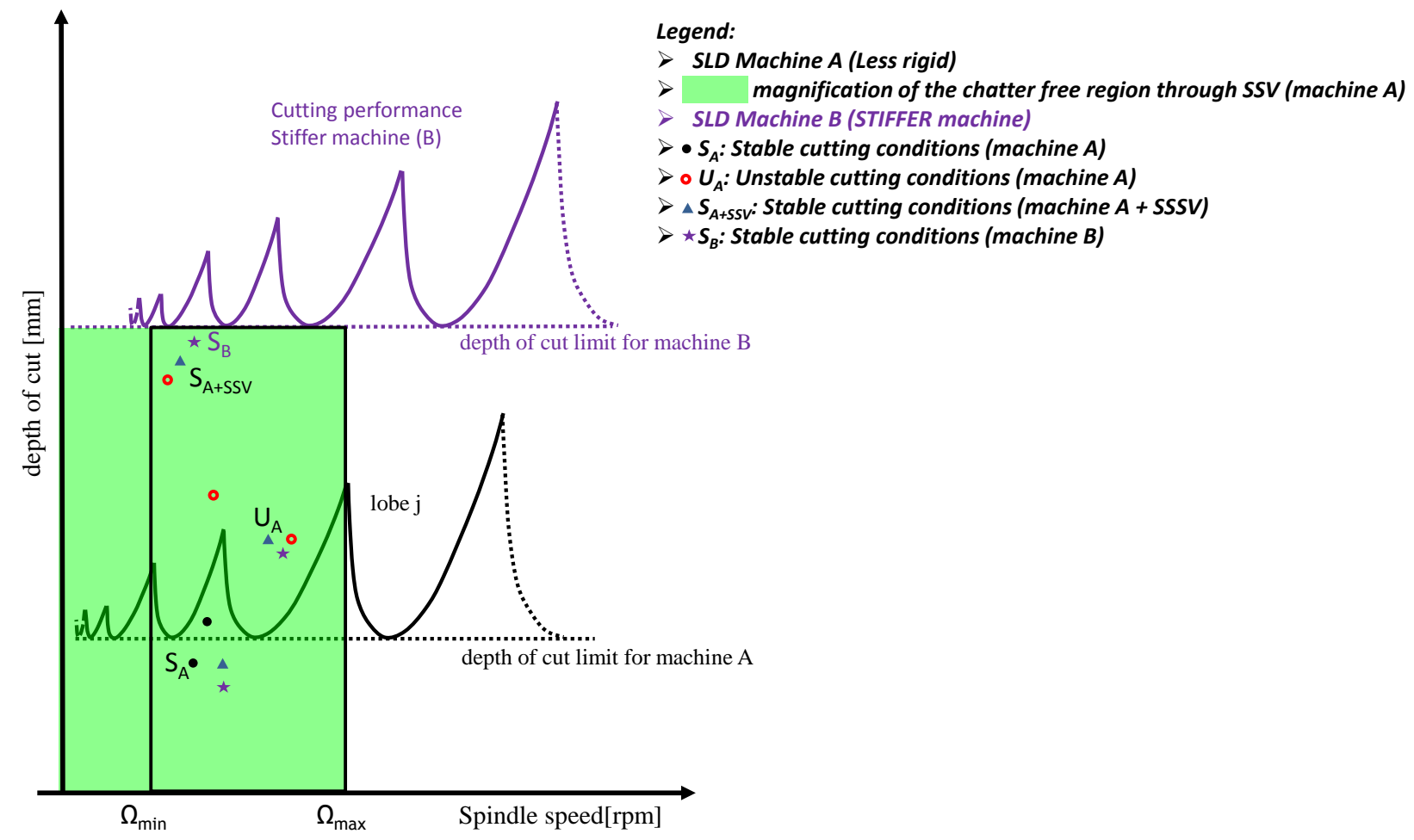

Fig. 1: SSSV effectiveness - scenario description

In this research, in order to cope with the described literature lack, an experimental campaign (tool wear tests) was carried out considering a steel turning application: the cutting speed and the modulation of the cutting speed are the main factors of the factorial design. The tool flank width was measured during the wear tests by means of a stereomicroscope. The carbide life is the main considered process response: the analysis of variance (ANOVA) was done on the data got from the wear tests. In order to interpret and justify the obtained results a SEM microscopy analysis was performed on each worn-out cutting edge: it was proved that a quite unusual mechanism fosters the insert coatings detachment. Referring to the specific literature, a similar wear mechanism was observed only for different tool-working materiallubricant combinations, that is in hard-to-cut materials dry processing (i.e. titanium alloys). 
The temperature close to the cutting edge was also measured in all the experimentally investigated cutting conditions to comprehend the origins of the observed wear mechanisms. The paper is organized as follows. The description of the experimental set-up together with materials and methods presentation are reported in section 2 . In section 3 , the experimental test results are reported and analyzed. In section 4, the analysis of the effects of SSSV on the main wear mechanisms (performed through a SEM (Zeiss EVO)) is reported. In section 5, conclusions and interesting future activities are outlined.

\section{Materials and Methods}

Cutting tool wear tests (turning) were carried out in order to analyze the effects of SSSV both on the life of the carbides and on the involved wear mechanisms. Tool life tests were performed following a full factorial design (as explained by Montgomery [12]) that considers two main factors, each with 2 levels:

1. Cutting speed $\left[\mathrm{V}_{\mathrm{cmin}} / \mathrm{V}_{\mathrm{cmax}}\right]: \mathrm{V}_{\mathrm{c} \min }=140 \mathrm{~m} / \mathrm{min}$ and $\mathrm{V}_{\mathrm{c} \max }=190 \mathrm{~m} / \mathrm{min}$ are respectively the lower level and the higher level for the cutting speed factor.

2. Cutting speed modulation [CSM/SSSV]. It means that SSSV can be switched on or turned off. Cutting tests can be thus performed at constant speed machining (CSM) or adopting SSSV.

The basic idea of the proposed experimental campaign is to compare the effects, on tool wear, of the modulation of the cutting speed to those due to the parameter that mostly affects the tool duration (cutting speed).

The flank wear average width $\left(\mathrm{VB}_{\mathrm{B}}\right)$ was monitored during the cutting tests. $\mathrm{VB}_{\mathrm{B}}=0.15 \mathrm{~mm}$ was used as the 'end of tool life' criteria. The life of the tool $\mathrm{Tl}$ that corresponds to $\mathrm{VB}_{\mathrm{B}}=0.15 \mathrm{~mm}$ is the main process response. Steel bars (UNI 39NiCrMo3, 255HB (UNI 7845-78)) hardened and tempered were used to perform the wear tests. A steel turning application was selected because, as presented by Albertelli et al. [11], for the cutting speeds typically adopted in steel machining and taking into account the limiting eigenmodes generally associated to tool dynamics $(70-160 \mathrm{~Hz})$, SSSV exhibited very interesting chatter suppression properties. SSSV is typically described by two main parameters: RVA and RVF, Eq. (1):

$$
\Omega(t)=\Omega_{0} \cdot\left(1+R V A \cdot \sin \left(R V F \cdot \Omega_{0} \cdot t\right)\right)
$$

RVA is the dimensionless spindle speed modulation amplitude (sinusoid amplitude/nominal spindle speed $\left(\Omega_{0}\right)$ ) while RVF is the dimensionless spindle speed modulation frequency (sinusoid frequency $/ \Omega_{0}$ ).

In the performed cutting tests the following SSSV parameters combination was selected: $R V A=0.3, R V F=0.1$. These parameters would assure relevant chatter suppression properties and higher stable depths of cut for the considered turning application, as shown by Albertelli et al. [11]. The tool life tests were performed following the standard IS0 3685:1993(E). A Stereomicroscope Optika SZN-T with Motic SMZ-168T support was used to measure flank wear width (VBB) during the cutting tests. More details on the performed wear measurements are reported in Albertelli et al. [13]. A carbide tool with a lead angle $\chi=90^{\circ}$ was adopted (ISO standard code: TNMG220404-M5 5615 with Al2O3-TiCN coatings) and fixed on tool holder, ISO code MTJNL2525M22. A detailed analysis of the coatings thickness will be further reported in section 4. Cutting fluid (oil-water emulsion) was used in order to reproduce realistic industrial machining conditions: it was adduced close to the cutting zone through nozzle, visible also in Fig. 2.

The other main cutting parameters adopted in the experimental campaign are: radial depth of cut $\mathrm{p}=2 \mathrm{~mm}$, feed rate $\mathrm{f}_{\mathrm{Z}}=0.2 \mathrm{~mm} / \mathrm{rev}$ and cutting fluid flow is equal to $\mathrm{ml}=2 \mathrm{l} / \mathrm{min}$. The cutting parameters were selected in order to being able to work in stable conditions as already explained in the introduction. Machining conditions $\mathrm{U}_{\mathrm{A}}$ (Fig. 1) can be representative for all the performed wear tests.

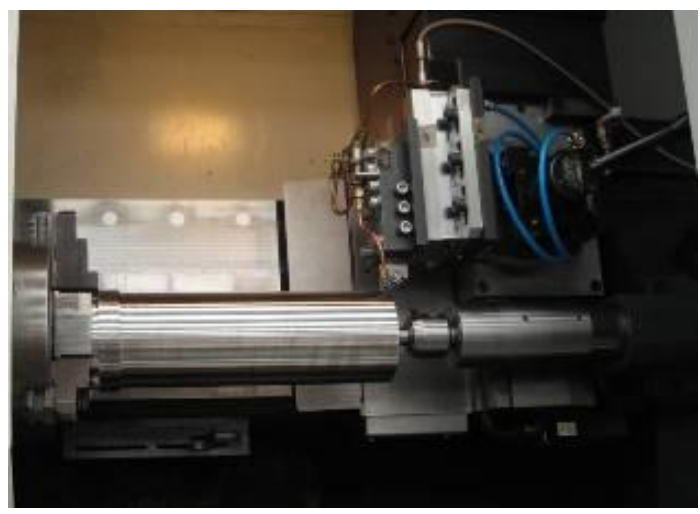

Fig. 2: Lathe SOMAB UNIMAB 400 and the experimental set-up 
The lathe (SOMAB UNIMAB 400) used to perform cutting tests is equipped with an analogical Numerical Control (NC). Refer to Albertelli et al. [13] for more details on the modifications made on the lathe to implement the speed modulation. Before performing the wear tests, it was verified that both the available spindle torque and spindle drive bandwidth were suitable to implement the SSSV for all the processed bar diameters. In order to prevent any effects, due to undesired factors, on the experimental results some other preliminary verifications were done. For instance, the steel microhardness were measured along the processed bar radial coordinate. The results of the analysis of variance (ANOVA) performed on microhardness data demonstrated that the machined steel was homogeneous. Moreover, preparatory cutting tests were also performed in order to verify the absence of undesired (i.e. due to regenerative chatter) vibrations in each combination of the selected cutting parameters. The verification was performed analyzing the spectrum of both the measured cutting forces and accelerations acquired during the prior tests.

\section{Experimental tool life results}

Tool wear cutting tests were done following a randomized run order. Experimental results are reported in Table 1: T1 is the observed tool life in each wear test considering the already defined "end of life" criteria.

\begin{tabular}{lll}
\hline $\mathrm{V}_{\mathrm{c}}[\mathrm{m} / \mathrm{min}]$ & SSSV/CSM & $\mathrm{Tl}[\mathrm{min}]$ \\
\hline 190 & $\mathrm{CSM}$ & 41.48 \\
190 & $\mathrm{SSV}$ & 27.13 \\
190 & $\mathrm{CSM}$ & 38.9 \\
140 & $\mathrm{SSV}$ & 89.1 \\
190 & $\mathrm{SSV}$ & 19.44 \\
140 & $\mathrm{CSM}$ & 122.41 \\
140 & $\mathrm{SSV}$ & 120.7 \\
140 & $\mathrm{CSM}$ & 140.6 \\
\hline
\end{tabular}

Table 1: Tool wear test results

The main effects plot (Fig. 3) roughly shows the influence of the studied factors on cutting edge life. A variancestabilizing transformation was carried out on the original data.

Main Effects Plot for Tool Tife "TI [min]" Data Means

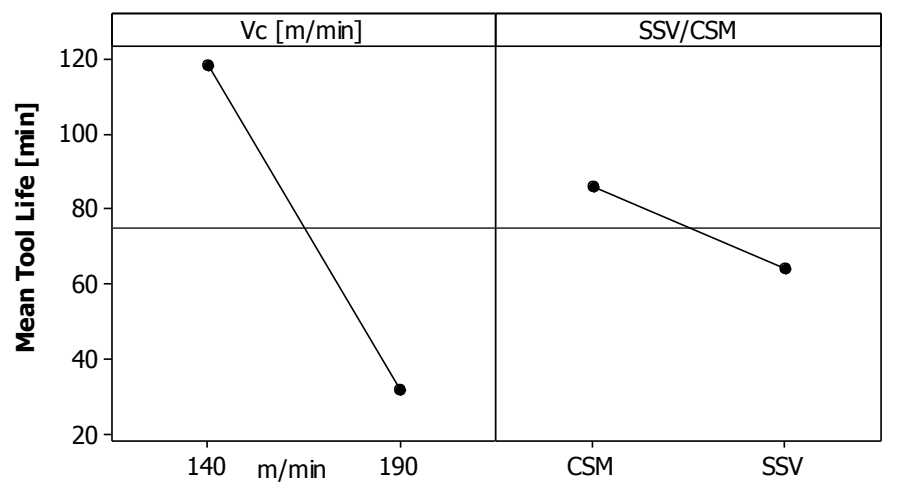

Fig. 3: Main Effects plot for the tool life

Considering the well known Taylor's equation, a logarithmic transformation (natural log) was done on the original data. Performing the ANOVA on the transformed data and not considering the cutting speed/SSSV interaction factor the following results have been obtained, Table 2. DF is the number of degrees of freedom, SS the sum of square, MS the mean square, $\mathrm{F}$ the Fisher's test and $\mathrm{P}$ the p-value linked to the result of each test.

A confidence interval $(\alpha=5 \%$.) for each single statistical test was considered, as suggested by Montgomery [12]. Both the analyzed factors (cutting speed and cutting speed modulation) affected the tool life Tl.

\begin{tabular}{llllll}
\hline Source & DF & SS & MS & F & P \\
\hline $\mathrm{V}_{\mathrm{c}}$ & 1 & 3.62188 & 3.62188 & 109.28 & 0
\end{tabular}




\begin{tabular}{llllll} 
CSM/SSSV & 1 & 0.31532 & 0.31532 & 9.51 & 0.027 \\
Error & 4 & 0.16571 & 0.03314 & & \\
Total & 7 & 4.10290 & & & \\
\hline
\end{tabular}

Table 2: ANOVA results, transformed data (natural log)

All the ANOVA hypotheses are verified and the results can be summarized as follows:

1. Anderson-Darling's test (normality) p-value $=0.99$

2. Bartlett's test $\mathrm{p}$-Value $=0.62$

3. Residual independency and normality are also verified

A detailed analysis on the power of the tests is reported in Albertelli et al. [13].

Considering that the Fisher's (F) test p-value linked to SSSV/CSM factor (Table 2) is quite low even if the power of the test is not very high, it can be finally concluded that the modulation of the cutting speed negatively affects the life of the tool. In the following section, a detailed analysis on the involved wear mechanisms is presented.

\section{Tool wear mechanisms analysis and results discussion}

In this section of the paper, the results of the analysis of the wear mechanisms occurred during the experimental campaign are reported.

In Fig. 4 are depicted the worn out flanks linked to all the experimentally tested cutting conditions. It can be observed that the spindle speed modulation caused a different wear footprint on the tool even if the difference is less manifest for the lower nominal cutting speed $(140 \mathrm{~m} / \mathrm{min})$. The analysis was extended to the rake face of the insert through a SEM.

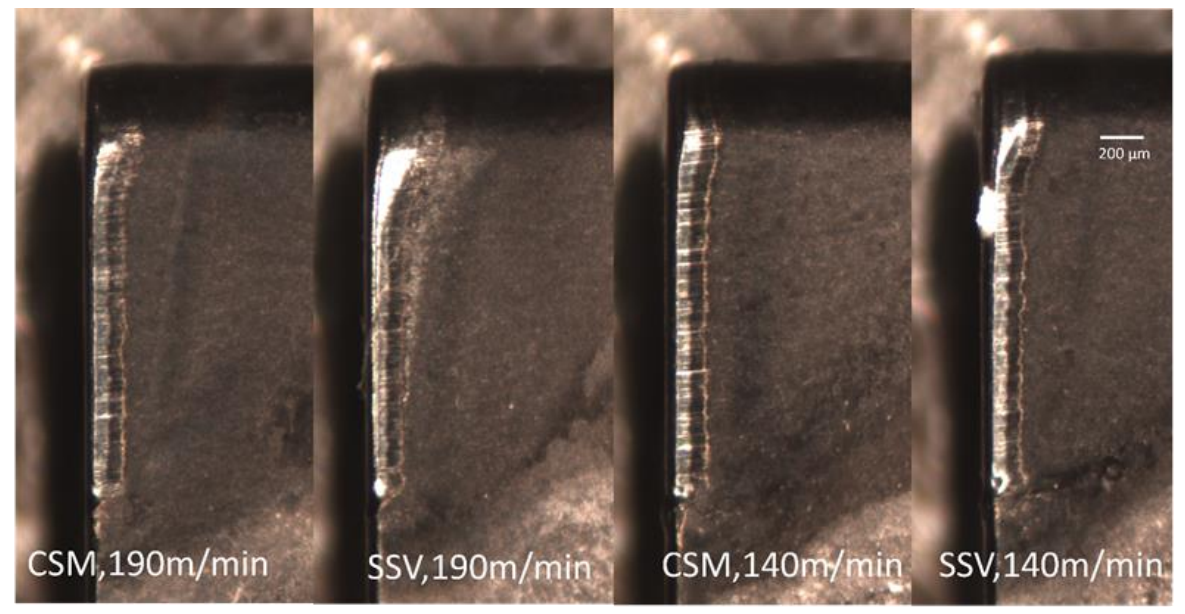

Fig. 4. flank wear at the end of the tool life (stereo-microscope)

The worn carbide surfaces were examined under a scanning electron microscope (SEM) equipped with an energy dispersive X-ray spectrometer (EDS).

The first analysis was performed on the cross section of a new cutting edge in order to be sure the tool complies with the specifications provided by the tool manufacturer. As can be observed in Fig. 5, the carbide tool (WC) exhibits two coatings: the TiCN layer and the $\mathrm{Al}_{2} \mathrm{O}_{3}$ layer. Different measurements of the thickness of the coatings were performed and the obtained results are summarized in Table 3. 


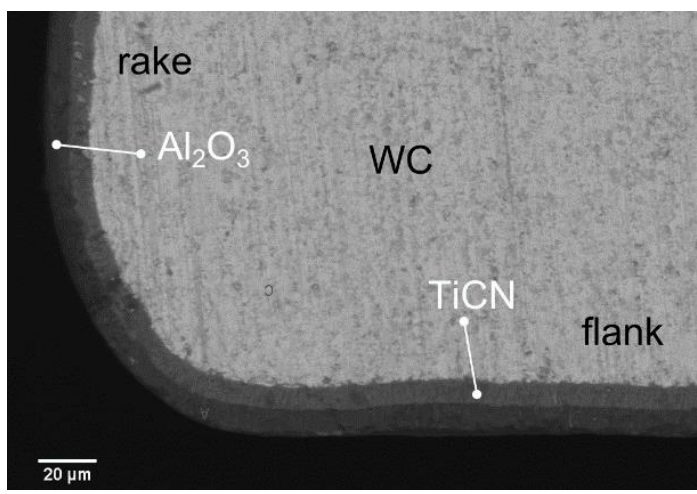

Fig. 5: Scanning electron micrograph of the cross-section of a new cutting edge

\begin{tabular}{lccc}
\hline coating & Mean thickness $[\mu \mathrm{m}]$ & Standard deviation $[\mu \mathrm{m}]$ & number of measurements \\
\hline $\mathrm{Al}_{2} \mathrm{O}_{3}$ & 8,99 & 1,03 & 30 \\
$\mathrm{TiCN}$ & 7,83 & 0,56 & 28 \\
\hline
\end{tabular}

Table 3: coatings thickness measurements (new tool)

The worn cutting edges were then analysed and the results are reported in Fig. 6. Both the rake and the flank wears are clearly visible: the main evident differences (considering CSM and SSSV) can be appreciated mainly focusing on the wear of the tool rake.

It can be easily observed, looking at Fig. 6, that all the inserts that had worked with SSSV exhibit a different wear "footprint". Indeed, they show a clearly visible damage of the coatings on the rake face and a less regular wear on the flank (visible in Fig. 4). 


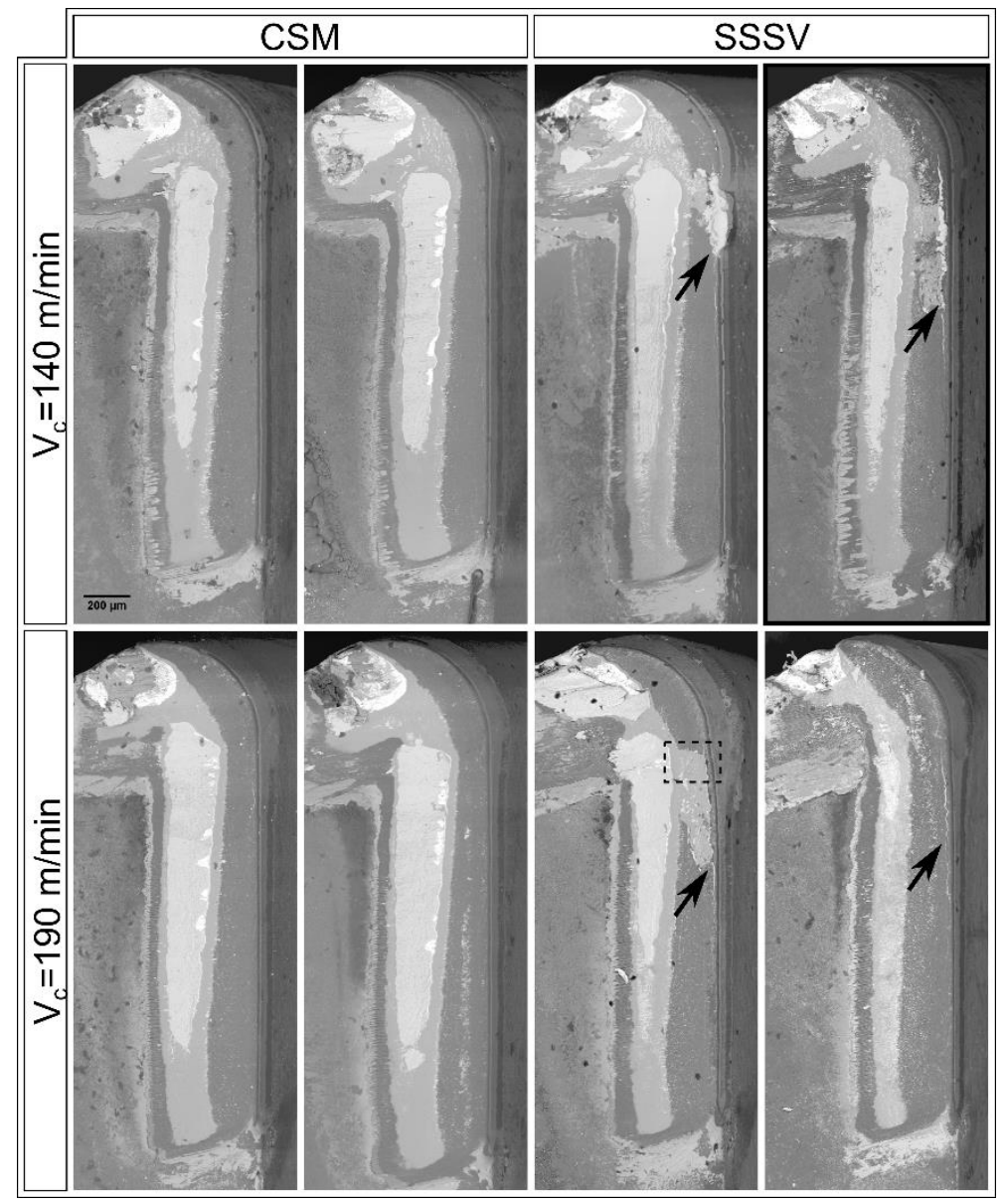

Fig. 6: Scanning electron micrographs of all the cutting edges used in the experimental campaign

Focusing on one of the tested tool (i.e. $\left(\mathrm{V}_{\mathrm{c}}=140 \mathrm{~m} / \mathrm{min}-\mathrm{SSSV}\right)$ rimmed in Fig. 6), all the involved wears mechanisms can be therefore analysed (Fig. 7): some of them were observed both for CSM and SSSV, others are associated only to SSSV machining.

The flank wear is mainly caused by abrasion: this effect can be observed both in Fig. 4 and in Fig. 8 where crosssections (obtained with the H-H section plane shown in Fig. 7) of different worn tools are reported. The abrasion wreak the wear on the flank in all the tested cutting conditions: an increasing wear can be appreciated moving toward the cutting edge (Fig. 7 and Fig. 8, regions tagged with the letters " $\mathrm{B}$ " and " $\mathrm{C}$ "), where the external coating $\left(\mathrm{Al}_{2} \mathrm{O}_{3}\right)$ was completely removed.

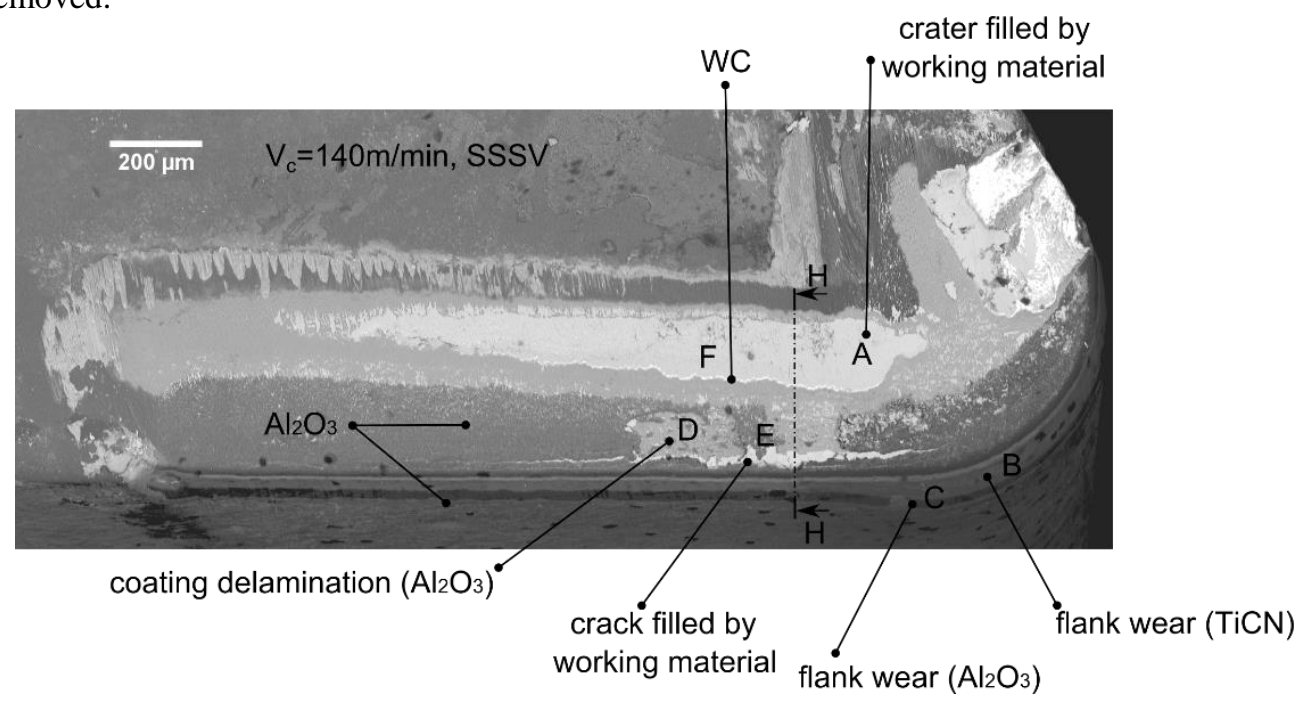

Fig. 7: Scanning electron micrograph of a worn tool $(\mathrm{Vc}=140 \mathrm{~m} / \mathrm{min}-\mathrm{SSSV})$, wear description 


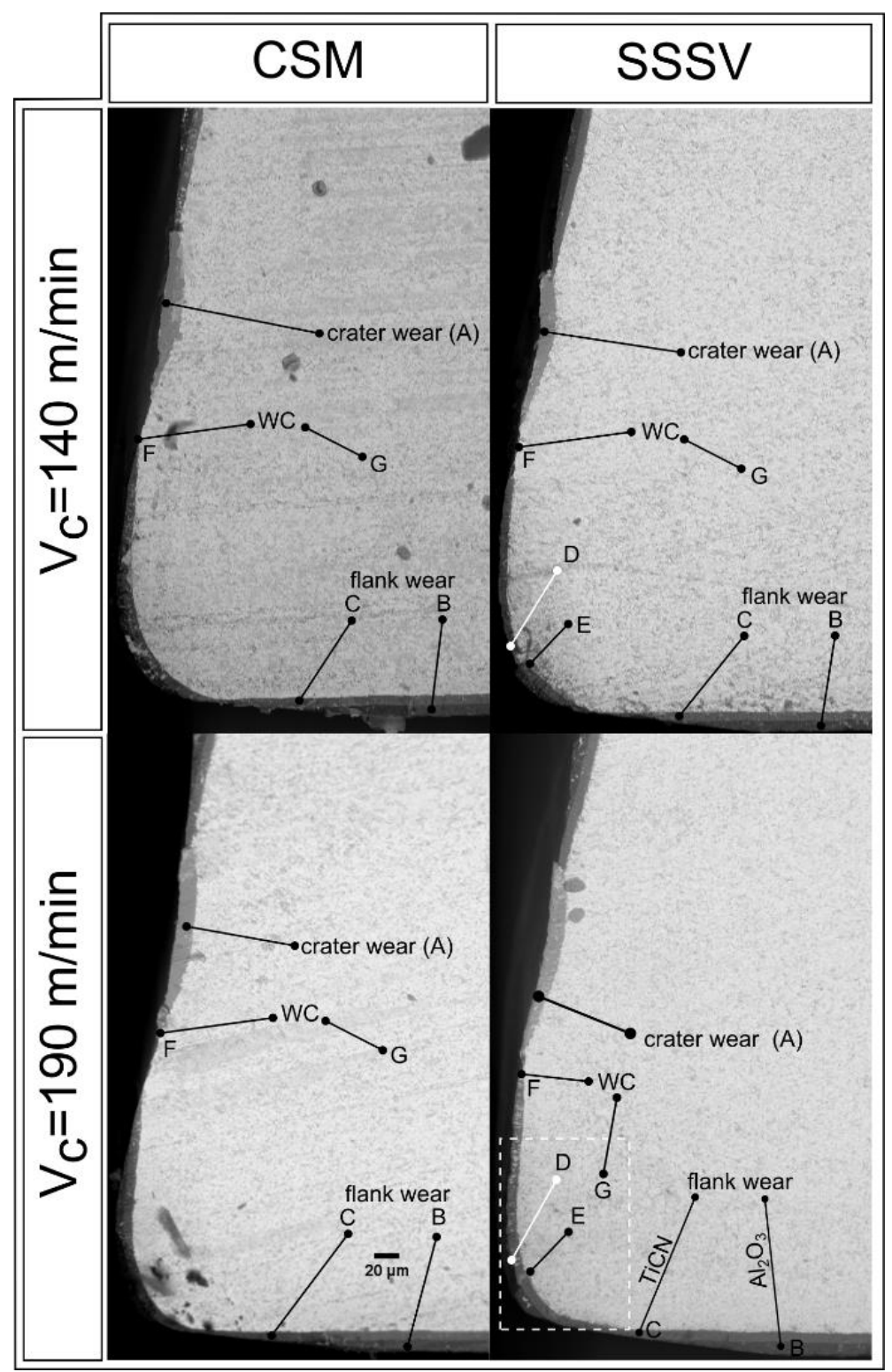

Fig. 8: Scanning electron micrographs of cross sections of worn tools (got using a section plane similar to the one reported in Fig. 7)

Focusing on the wear on the tool rake it can be stated that, depending on the rake face region, different mechanisms were involved. Both in CSM and SSSV a crater is visible in the inner region of the rake face (label "A" in Fig. 7 and Fig. 8). The crater is mainly due to a combined effect of abrasion and adhesion. This combined effect was observed also by Che Haron et al. [14]. Dearnley [15] performed a study of wear mechanisms on similar tool-workpiece materialcutting conditions combinations. Chubb and Billingham [16] observed that the coating breakdown is enhanced by thermal cracking.

In the first wear stage, friction between the chip and the tool progressively removes (up to complete removal) the coatings from the tool. From that stage, the workpiece material starts to adhere to the substrate: when a portion of this material is removed from the tool due to the mechanical action involved in the material removal process, it brings with it part of the substrate hence fostering the crater enlargement.

The EDS analysis reported in Table 4 (point A in Fig. 9) confirms the adhesion of workpiece material on the crater: high concentration of iron (Fe) can be appreciated.

While the wear mechanism described so far is quite common, a quite unusual mechanism, especially considering a wet steel turning, was observed on the rake face, closer to the cutting edge. This mechanism was observed only when the SSSV had been adopted. Indeed, delamination of $\mathrm{Al}_{2} \mathrm{O}_{3}$ coatings occurred. As can be observed in Fig. 7, Fig. 8 and Fig. 9 (label D), the delamination of the external coating is mainly due to the formation of a crack (label E) that extends itself along a quite relevant portion of the engaged cutting edge.

Fig. 10 shows the details, focusing closely on the dotted area pointed out in Fig. 8, of the crack formation and of the coating delamination $\left(\mathrm{Al}_{2} \mathrm{O}_{3}\right.$ layer). 


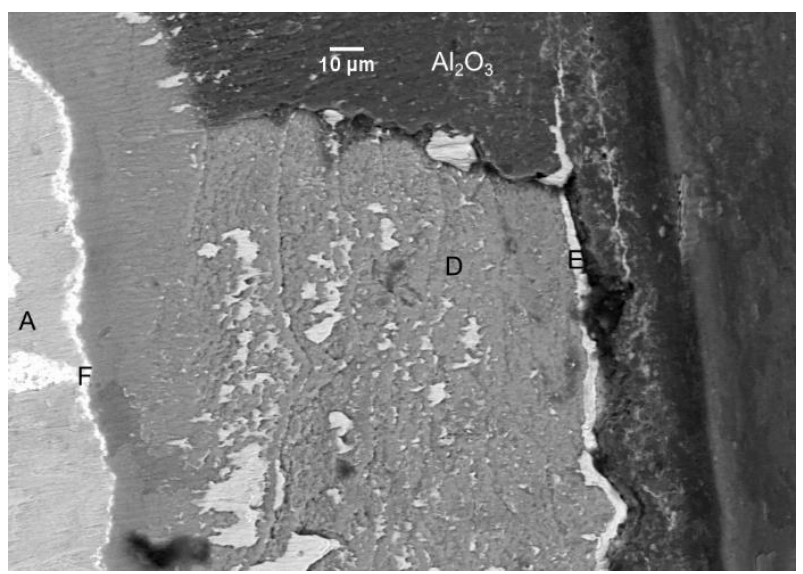

Fig. 9: Scanning electron micrograph (190m/min, SSSV), zoom of the dotted region depicted in Fig. 6 (coating delamination)

\begin{tabular}{|l|l|l|l|l|}
\hline position & Weight \%Al & Weight \% Ti & Weight \% Fe & Weight \% W \\
\hline E & 15.17 & 2.66 & 79.62 & - \\
\hline D & 0.55 & 96.62 & 0.94 & - \\
\hline A & 0.42 & - & 91.26 & 6.15 \\
\hline F & - & 8.02 & 3.89 & 87.66 \\
\hline
\end{tabular}

Table 4: EDS analysis, analysis performed on measurement points reported in Fig. 9

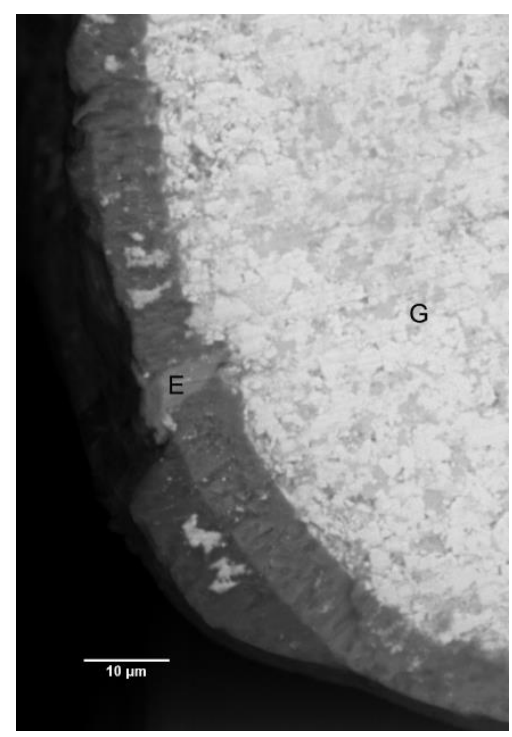

Fig. 10: Scanning electron micrograph (190m/min, SSSV), zoom in of the dotted region depicted in Fig. 8 coating delamination

On the contrary, the coating delamination is quite a common phenomenon in "hard to cut materials" machining. Nouari and Ginting [17] observed a severe delamination of multi-layer CVD-coated (chemical vapour deposition) alloyed carbide tool in dry titanium alloy milling. Also Jawaid et al. [18] observed that coating delamination was one of the wear mechanisms that occurs in titanium milling. This suggests that SSV thermally and mechanically overloads, even in steel cutting, the tool, fostering wear mechanisms as in hard to cut material dry processing.

On the formation of cracks and on the consequent delamination of the coatings of the carbide tool in hard-to-cut machining, the specific literature so far has been ambiguous. Some works stated that this wear mechanism is mainly led by the diffusion of atoms of tool material that is promoted by high cutting temperatures. Nouari and Ginting [17] set a 
FE (finite element) model to better predict the thermal map of the tool and to understand the mechanism that causes the breakage of the coating and the formation of the micro cracks. Ginting and Nouari [19] reported also an analysis of the worn tool performed with SEM. It was stated that, in order to activate such diffusion mechanism, the cutting temperature has to reach a threshold equal to $850^{\circ} \mathrm{C}$. At such a high temperature, the cutting tool material partially loses its hardness. Meanwhile, due to the high pressure, the area of contact between the tool and the chip will be maximized. This promotes adhesion at the tool-chip interface. Further, due to high temperature, the thermal conductivity of the coating constituents will drop and the different values of the thermal conductivity of the coating layers will cause a significant temperature gradient to take place. A corresponding diffusion gradient accompanies the thermal gradient that helps removing the adhesive surface between the tool and the coating, as explained by Abdel-Aal et al. [20]. Other works asserted that the delamination could be provoked by different coefficients of thermal expansion among the coating layers and between the coating and the carbide. For instance, Nouari et al. [21] developed a theory that estimates the resistance of materials to the formation of micro cracks as a function of the following coating-tool materials pair properties: tensile strength, Young's Modulus, coefficient of thermal expansion and the thermal conductivity. They defined a ratio of resistance that is linked to the weakness of the materials link: much the index differs from one, weaker is the link of two materials pair. Moreover, the authors considered how the temperature affects the defined ratio.

Since the diffusion mechanisms described in the cited and analysed works are very common in hard to cut materials dry machining, they seem quite unlike in wet steel turning where cutting temperatures typically do not exceed the diffusion activation temperature threshold, as stated by Grzesik [22]. The cracks formation and the coating delamination observed after SSSV cutting tests have not to be associated solely to thermal issues.

In order to support the previous considerations and to deepen the analysis, the temperature close to the rake face was experimentally measured (sampling frequency equal to $100 \mathrm{~Hz}$ ) for all the adopted cutting conditions. A thermocouple (0.5mm diameter) was fit into a hole in the carbide bit, as shown in Fig. 11. Even if the temperature measurements were done quite far from the primary shear zone it can be observed (Fig. 12) that:

- The cutting temperature is strictly related to cutting velocity also during SSSV turning: the temperature oscillation due to speed modulation can be appreciated.

- It can be supposed that the temperature oscillation is much more evident on the rake face

- In SSSV cuttings the average temperatures seem to be equal to the ones measured during the corresponding CSM cuttings

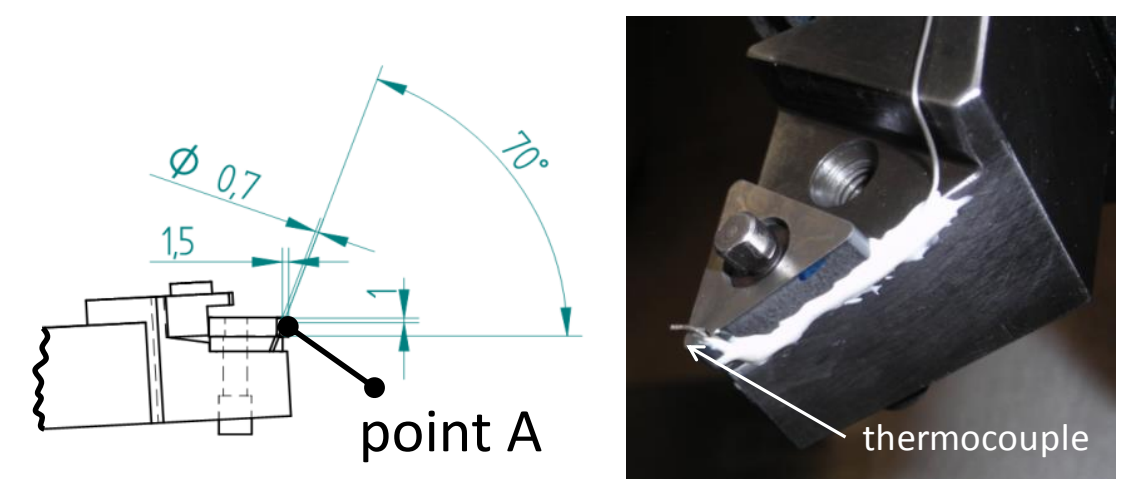

Fig. 11: Thermocouple location inside the tool (point A) 

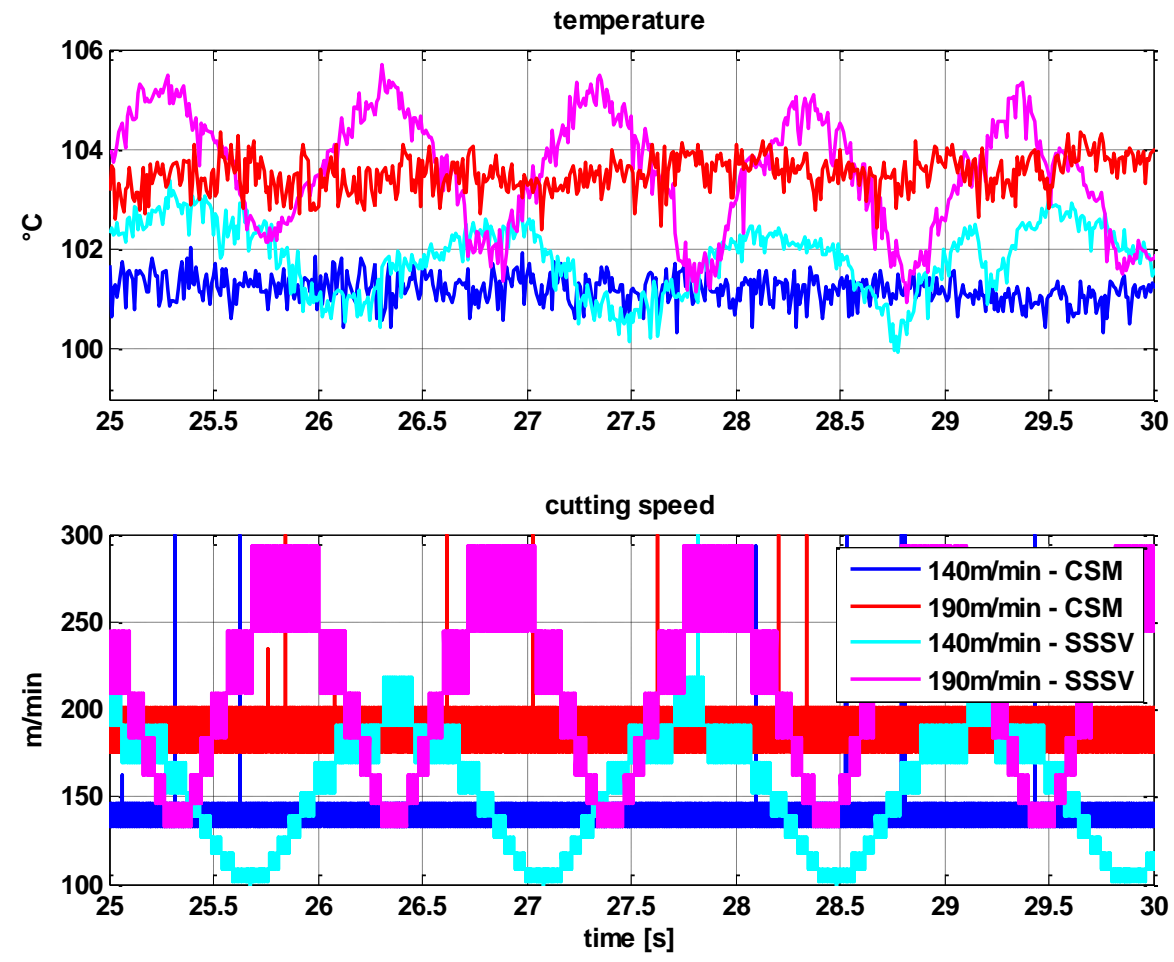

Fig. 12: a) temperature (point A) measurement during cutting tests, b) cutting speed from spindle encoder

Considering the first two observations, it can be asserted that the tool overheating due to the spindle speed modulation (even if for very short time intervals) could be the cause of the early cutting tool delamination and wear.

This hypothesis has to be rejected by analyzing the cutting tests performed at $140 \mathrm{~m} / \mathrm{min}$ (SSSV activated): it is very likely, given that all the previous considerations, that the maximum cutting temperature on the rake is smaller than the temperature observed in the tests performed at 190m/min in CSM regime. This brings us to the conclusion that the tool delamination observed in SSSV cutting and the involved higher tool wear are not only related to thermal issues even if temperature oscillations can entail, due to different coatings thermal expansion coefficients, a thermal fatigue effect.

In order to examine in detail the open issue and better understand the reasons of such an enhanced tool wear in SSV cutting, additional cutting tests and SEM analysis were performed. The additional analysis is useful to figure out two reasonable scenarios:

- The crack formation is due to a thermo-mechanical fatigue

- The crack formation is due to a too high tool-workpiece contact pressure peak due to SSSV cutting mechanics as numerically simulated by Chiappini et al. in [23]

In order to investigate these two hypotheses a sequence of interrupted tool wear tests (the cutting time $\mathrm{T}$ is progressively increasing) were performed. After each test $\left(V_{c}=190 \mathrm{~m} / \mathrm{min}, \mathrm{f}_{\mathrm{z}}=0.2 \mathrm{~mm} / \mathrm{rev}\right)$, tool wear was analysed through SEM in order to capture the initial phases of the crack formation. As can be noted in Fig. 13 (a), after the first interrupted cutting test $\left(\mathrm{T}_{1}=21.03 \mathrm{~s}\right)$, the crack has not still come out while the initial formation of the crack is clearly visible observing Fig. 13 (b) and Fig. 14 (cutting time $\mathrm{T}_{2}=110.4 \mathrm{~s}$ ). It denote that the overload involved in SSSV cutting does not instantaneously create cracks in the coating. This analysis allows to deduce that the crack formation is mostly due to thermo-mechanical fatigue and not to the high tool-chip high contact pressure entailed in SSSV cutting. 


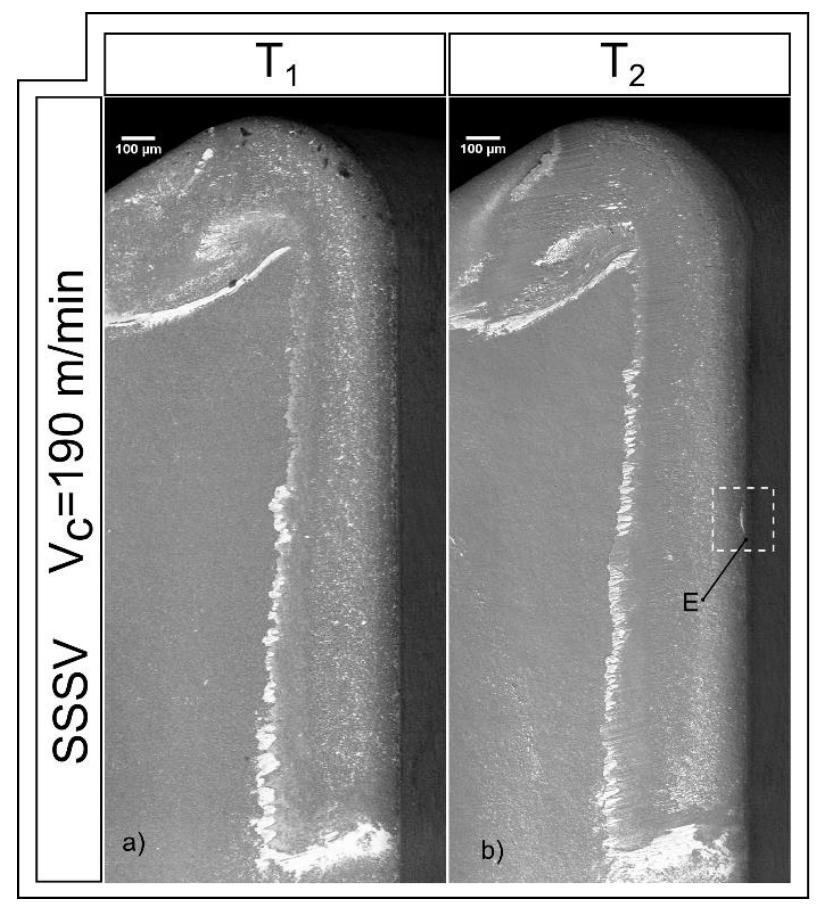

Fig. 13: Scanning electron micrograph (190m/min, SSSV), early crack formation

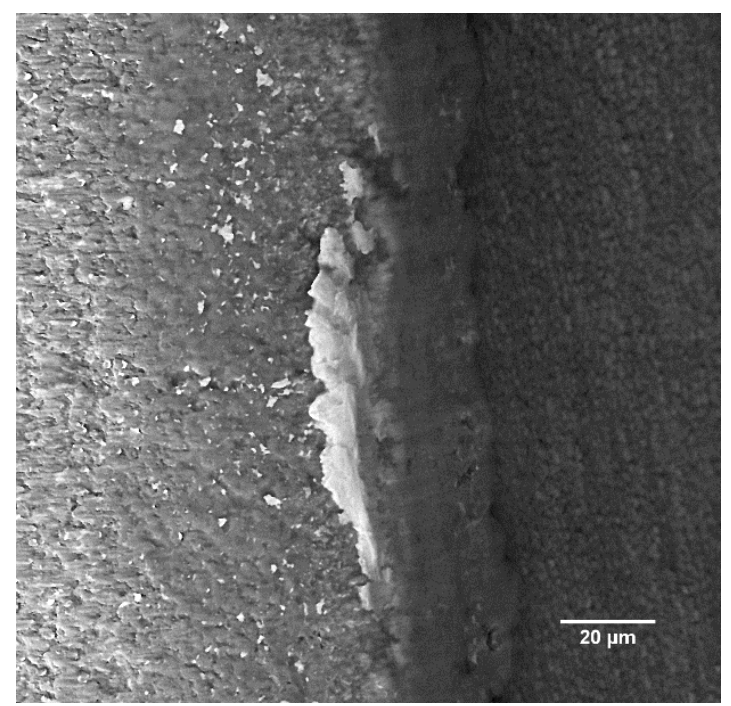

Fig. 14: Scanning electron micrograph (190m/min, SSSV), zoom of the dotted region depicted in Fig. 13 (early crack formation)

\section{Conclusions and future works}

In this paper, the effects of sinusoidal spindle speed variation SSSV on tool wear in turning have been studied.

As anticipated in the introduction, this needs to be taken into consideration in a comprehensive evaluation of the SSSV capabilities.

A full-factorial design was adopted to perform tool wear tests: cutting speed and the modulation of the cutting speed were analyzed process factors. Tool life was the main considered process response. The analysis of variance (ANOVA) performed on the experimental data showed that also the cutting speed modulation affects the carbide life: SSSV reduces the tool duration.

In the second part of the paper, an energy dispersive X-ray spectrometer (EDS) analysis performed on the worn tools with a scanning electron microscope (SEM) revealed, only for the inserts used in SSSV tests, the effects of an unusual wear mechanism. A coating delamination has been observed: cracks filled with working material foster the coating delamination. A similar wear mechanism was also reported in other 
scientific works but referring to titanium alloys dry machining that can be considered a very severe cutting condition. This mechanism is quite unlike in wet steel turning, no other researches that dealt with steel machining have described this wear mechanism. This demonstrates that SSSV entails a thermo-mechanical tool overload like in hard to cut machining. Additional cutting tests and SEM analysis confirm that the tool delamination is mainly due to thermo-mechanical fatigue effect. Although the study of the wear of the tool is a relevant research branch, no previous works that studied the effects of SSSV on tool wear have been found in literature. The presented research is innovative; the obtained results are interesting and very useful to critically evaluate the SSSV implementation feasibility also in industrial applications. Moreover, the presented research results foster new interesting developments: a better understanding of the involved phenomena for example using Finite Element Methods and the creation of a tool life model in SSSV cutting that can be used, as already described in the introduction, to evaluate the real convenience of adopting SSSV.

\section{Acknowledgements}

This research has been carried out with financial support from Ministero Sviluppo Economico (Michelangelo Project, Industria 2015 MI01-00237). The authors thank eng. Fabio Bruzzi and Corrado Buroni that helped the authors in this work.

\section{References}

[1] Altintas Y, Weck M (2004) Chatter stability of metal cutting and grinding. CIRP Annals - Manufacturing Technology $53(2): 619-642$

[2] Kayhan M, Budak E (2009) An Experimental Investigation of Chatter Effects on Tool Life. Proc. IMechE, Part B: Journal of Engineering Manufacture 223 (11):1455-1463

[3] Siddhpura M, Paurobally R (2012) A review of chatter vibration research in turning. International Journal of Machine Tools and Manufacture 61:27-47

[4] Inamura T, Sata T (1974) Stability Analysis of Cutting Under Varying Spindle Speed. CIRP Annals 23 (1):119-120

[5] Yilmaz A, AL-Regib E, Ni J (2002) Machine Tool Chatter Suppression by Multi-Level Random Spindle Speed Variation. Trans. ASME Journal of Manufacturing Science and Engineering 124 (2):208-216

[6] Insperger T, Schmitz T, Burn TJ, Stépán G (2003) Comparison of analytical and numerical simulations for variable spindle speed turning. Proceedings of IMECE'03 International Mechanical Engineering Congress, Washington, D.C., United States:1-7

[7] Radulescu R, Kapoor SG, DeVor RE (1997) An Investigation of variable spindle speed face milling for tool-work structures with complex dynamics, part 1: simulation results. Transactions of ASME Journal of Manufacturing Science and Engineering 119:266-272

[8] Jayaram S, Kapoor SG, DeVor RE (2000) Analytical stability analysis of variable spindle speed machining. Transactions of ASME, Journal of Manufacturing Science and Engineering 122:391-397

[9] Insperger T, Stépán G (2004) Stability analysis with periodic spindle speed modulation via semidiscretization. Journal of Vibration and Control 10:1835-1855

[10] Zatarin M, Bediaga I, Munoa J, Lizarralde R (2008) Stability of milling processes with continuous spindle speed variation: analysis in the frequency and time domains, and experimental correlation. CIRP Annals 57:379-384

[11] Albertelli P, Musletti S, Leonesio M, Bianchi G, Monno M (2012) Spindle speed variation in turning: technological effectiveness and applicability to real industrial cases. The International Journal of Advanced Manufacturing Technology 62 (1):59-67

[12] Montgomery DC (2001) Design and Analysis of Experiment, fifth ed. John Wiley and Sons

[13] Albertelli P, Mussi V, Ravasio C, Monno M (2012) An experimental investigation of the effects of Spindle Speed Variation on tool wear in turning. Process Machine Interaction Conference Procedia CIRP 4:29-34

[14] Che Haron CH, Ginting A, Goh JH (2001) Wear of coated and uncoated carbides in turning tool steel. Journal of Materials Processing Technology 116(1):49-54

[15] Dearnley PA (1985) Rake and flank wear mechanism of coated and uncoated cemented carbides. Journal of Engineering Materials and Technology 107:68-82

[16] Chubb JP, Billingham J (1980) Coated cutting tools - a study of wear mechanisms in high speed machining. Wear 61:556-559

[17] Nouari M, Ginting A (2006) Wear characteristics and performance of multi-layer CVD-coated alloyed carbide tool in dry end milling of titanium alloy. Surface and Coatings Technology 200(18-19):5663-5676

[18] Jawaid A, Sharif S, Koksal S (2000) Evaluation of wear mechanisms of coated carbide tools when face milling titanium 
alloy. Journal of Materials Processing Technology 99(1-3):266-274

[19] Ginting A, Nouari M (2006) Experimental and numerical studies on the performance of alloyed carbide tool in dry milling of aerospace material. International Journal of Machine Tools and Manufacture 46(7-8):758-768

[20] Abdel-Aal HA, Nouari M, Mansori Mel (2009) Tribo-energetic correlation of tool thermal properties to wear of WCCo inserts in high speed dry machining of aeronautical grade titanium alloys. Wear 266 (3-4):432-443

[21] Nouari M, Abdel-Aal HA, El Mansori M (2006) Analysis of coating delamination under extreme contact loading. Tribology Letters 23:39-45

[22] Grzesik W (1999) Experimental investigation of the cutting temperature when turning with coated indexable inserts. International Journal of Machine Tools and Manufacture 39(3):355-369

[23] Chiappini E, Tirelli S, Albertelli P, Strano M, Monno M (2014) On the mechanics of chip formation in Ti6Al4V turning with spindle speed variation. International Journal of Machine Tools and Manufacture 77(0):16-26 